\title{
Food waste volume and composition in households in Greece
}

\author{
Abeliotis K.*, Lasaridi K., Boikou K. and Chroni C. \\ School of Environment, Geography and Applied Economics, Harokopio University, El. Venizelou 70, 17671 Athens, Greece \\ Received: 06/05/2019, Accepted: 28/08/2019, Available online: 09/09/2019 \\ *to whom all correspondence should be addressed: e-mail: kabeli@hua.gr \\ https://doi.org/10.30955/gnj.003144
}

\section{Abstract}

The purpose of this paper is the presentation of the results compiled from self weighing of household food waste and self filling of waste collection diaries that took place in Greece. A diary was compiled and given to 101 urban households in various areas of the country. The participants were asked to weigh and write down in the diary every food item wasted in their households for two full weeks (i.e., 14 days). The total per capita food waste generation in Greece is estimated to be 76.1 ( \pm 68.3 ) $\mathrm{kg} / \mathrm{inh}-\mathrm{y}$. This figure is divided into the avoided food waste fraction which equals to $25.9( \pm 34.9) \mathrm{kg} / \mathrm{inh}-\mathrm{y}$, and the unavoidable fraction which is estimated to be $50.2( \pm 47.1)$ $\mathrm{kg} / \mathrm{inh}-\mathrm{y}$. The use of diaries for recording food that is thrown away from households is a methodology that underestimates the food wasted in households because households tend to be cautious when they know that they have to weigh and report the amount of food that they throw away. The current research is the first of its kind, presenting actual field data for food waste generation by households in Greece.

Keywords: Quantification, household food waste, selfreporting, waste compositional analysis.

\section{Introduction}

Food wastage is a global research issue due to its economic, environmental and social impacts. Food wastage happens in each one of the key food supply stages. Households are significant food waste producers, especially in the developed countries of the world (Sharp et al., 2010; European Commission, 2010). However, data on the quantification of the actual food waste generation by households are very scarce in the literature and not easily comparable due to the vast definitions and assessment methodologies applied to describe and measure the problem (Schneider, 2013). Usually, researchers refer to lump numbers reported by well-respected organisations such as the United Nations, which estimated at 95-115 kg/year the per capita food waste generation in Europe and North-America (Gustavsson et al., 2011), and the European Commission which reported the value of $179 \mathrm{~kg} /$ person/year as the total amount of food waste generated by citizens in the EU27 countries (European Commission, 2010).
Focusing on the developed countries, a closer look in the literature reveals that Szabó-Bódi et al. (2018) report a value of $68.06 \mathrm{~kg}$ per capita (including liquid waste) generated annually by the households in Hungary. Deley and Brunner (2018), based on a self-reported survey showed $8.9 \mathrm{~kg}$ of avoidable and possibly avoidable household food waste per capita per year in Switzerland. Similarly, the mean amount of avoidable food waste reported for Finland was $63 \mathrm{~kg}$ per household or $23 \mathrm{~kg}$ per person (Koivupuro et al., 2012). In the UK, Quested et al. (2013) reported that in 2010 avoidable food and drink waste corresponded to $160 \mathrm{~kg}$ per household and was equivalent to $12 \%$ of the food and drink entering the home (Quested et al., 2013). Moving on to North America, Pariseau et al. (2015) estimated a total value of $218.4 \mathrm{~kg}$ per capita annually generated by the households in Ontario, Canada, while in the US, Thyberg and Tonjes (2016) report that Americans dispose over 0.6 pounds (approx. $272 \mathrm{~g}$ ) of food waste per person per day (which corresponds to $99.28 \mathrm{~kg}$ per capita annually), without any distinction made between avoidable and non avoidable.

However, all of the aforementioned numbers are not easily comparable. The international literature reports that measurement of food waste generation by households can be performed either a) by asking households to self weigh their food waste or b) by weighing the generated food waste by households using a centrally designed approach by waste managers, such as the municipalities. More specifically, self weighting can be used effectively in small group activities, with sample sizes being small, usually 50-60 households, if carried out with regular data collection (Zorpas and Lasaridi, 2013). Once again, literature reveals these two different approaches: Szabó-Bódi et al. (2018) examine food waste generation by 100 households in Hungary. The researchers used a kitchen scale and a datasheet in order to collect the required data. The survey took place in 2016 for a period of one week. In a similar survey, Pariseau et al. (2015) examine the generation of food waste by 222 households in the area of Ontario in Canada. The authors used the weighing sampling method of the source separated organic waste generated by the households and placed on the curb for collection by the municipality. 
Focusing on Greece, previous research has shown that Greek consumers have positive attitudes towards food waste prevention and that their habits are close to the good practices suggested in the literature for reducing food waste (Abeliotis et al., 2014; Ponis et al., 2017). However, there is a gap regarding the comprehension of the food labels (Abeliotis et al., 2014). It was also found that better cooking skills are associated with better handling of leftovers and therefore with food waste prevention in Greece (Abeliotis et al., 2016). However, so far, research focusing on food waste in Greece was based on public survey questionnaires. There is a clear lack of field data on the actual food waste quantities that are generated in Greece.

The aim of this manuscript is the presentation of the results compiled from self weighing of household food waste and self filling of waste collection diaries that took place in Greece. The current research is the first of its kind, presenting actual field data for food waste generation by households in Greece.

\section{Materials and methods}

In order to estimate the food waste generation by Greek households, a diary was compiled and given to 101 urban households in various areas of the country in the period summer of 2013 and winter of 2014. At first, all the selected households were contacted by an open call by their municipalities for an educational and training event on food waste prevention and home composting. During this event, home composters were given to the interested citizens. The citizens that volunteered for home composting, were also required to fill in a diary which was aiming to estimate the generated food waste by the Greek households. Along with the diary, digital scales were given to the participating households in order to help them weigh the food waste generated within their premises. Overall, the participants in the field study were all volunteers. No direct monetary incentive was given to them for their participation.

The participants were asked to weigh and write down in the diary every food item wasted in their households for two full weeks (i.e., 14 days). The participants were asked to fill in the diaries during an average period of household activities with no special occasions (such as birthdays) which could distort the measurements (Visschers et al., 2016). Moreover, written instructions were given to the participating households so that all participants had the same definition of food waste, as Visschers et al. (2016) recommend. The participants were asked to weight and write down both the avoidable (i.e. edible), in addition to the unavoidable (e.g. fruit skins and vegetable trimmings) food waste fractions. The members for each household were also recorded. Self weighting requires close interaction with the householder because sometimes participants are forgetting or are choosing which items to record (Zorpas and Lasaridi, 2013). Therefore, the researchers were contacting the participating households via telephone every second day in order to remind them to fill the diary properly. At the end of the filling period, the diaries were collected and their input was coded into a spreadsheet. Grouping and analysis of the coded information by the researchers followed. Once the key results were extracted for 14 days, they were extrapolated to an annual basis. Moving on to its classification, food waste can be classified based on different approaches. The most typical approach is to classify food waste as being either avoidable or unavoidable (WRAP, 2009). Emphasis is placed on the avoidable fraction, due to its prevention potential. The overall results are presented in the next section.

\section{Results and Discussion}

A total of 101 households participated in the study. This sample size is comparable to other similar studies (Szabó-Bódi et al., 2018; Pariseau et al., 2015). The distribution of the family members within these households is presented in Table 1 . Based on the results of the 2011 census in Greece, the mean size of the household is 2.6 persons (Helstat, 2014). Therefore the distribution of the household members in our sample is representative of the population in Greece.

Table 1. Demographics of the study

\begin{tabular}{cccccccc}
\hline Family members & $\mathbf{1}$ & $\mathbf{2}$ & $\mathbf{3}$ & $\mathbf{4}$ & $\mathbf{5}$ & $\mathbf{6}$ & Total \\
\hline Number of households & 11 & $25^{*}$ & 23 & 28 & 12 & 2 & 101 \\
\hline \% within households & 10.9 & 24.7 & 22.8 & 27.7 & 11.9 & 2.0 & 100 \\
\hline
\end{tabular}

*For instance, this figure states that 25 households with 2 members participated in the study. These households correspond to $24.7 \%$ of the total number of households that participated in the study.

Based on the mean values resulting from the 101 households, the total per capita food waste generation in Greece is estimated to be $76.1( \pm 68.3) \mathrm{kg} / \mathrm{inh}-\mathrm{y}$ (see Table 2 ). This figure is divided into the avoided food waste fraction which equals to $25.9( \pm 34.9) \mathrm{kg} / \mathrm{inh}-\mathrm{y}$ and the unavoidable fraction which is estimated to be $50.2( \pm 47.1)$ $\mathrm{kg} / \mathrm{inh}-\mathrm{y}$. Note that this figure only refers to households, i.e. does not include data of the upstream (to the household) stage of the food supply chain. Note also that those figures have a very high standard deviation, an indication of the very different behaviours among the households regarding the food they waste, in addition to the shortcomings of the methodological approach. However, despite the high standard deviation, these figures are within the range that both the FAO and the EU report for food waste generation by the Europeans (European Commission, 2011; European Parliament, 2012; FAO, 2014). 
Table 2. Annual per capita food waste generation in Greece for various household sizes (kg/inh-y)

\begin{tabular}{cccccccc}
\hline Members & $\mathbf{1}(\mathbf{n}=\mathbf{1 1})$ & $\mathbf{2}(\mathbf{n}=\mathbf{2 5})$ & $\mathbf{3}(\mathbf{n}=\mathbf{2 3})$ & $\mathbf{4} \mathbf{( n = 2 8 )}$ & $\mathbf{5}(\mathbf{n}=\mathbf{1 2})$ & $\mathbf{6}(\mathbf{n}=\mathbf{2})$ & All $(\mathbf{n}=\mathbf{1 0 1})$ \\
\hline Avoidable & $38.7( \pm 24.8)^{*}$ & $29.5( \pm 39.0)$ & $29.0( \pm 49.6)$ & $20.3( \pm 21.9)$ & $17.9( \pm 25.6)$ & $2.2( \pm 2.0)$ & $25.9( \pm 34.9)$ \\
\hline Unavoidable & $37.8( \pm 38.6)$ & $53.0( \pm 43.3)$ & $55.5( \pm 52.6)$ & $60.6( \pm 54.8)$ & $24.5( \pm 22.0)$ & $31.0( \pm 11.4)$ & $50.2( \pm 47.1)$ \\
\hline Total & $76.5( \pm 44.6)$ & $82.5( \pm 72.7)$ & $84.5( \pm 82.0)$ & $80.9( \pm 70.0)$ & $42.4( \pm 40.7)$ & $33.2( \pm 29.4)$ & $76.1( \pm 68.3)$ \\
\hline
\end{tabular}

*Numbers in parentheses correspond to the standard deviation of each figure.

The number of members in the household has a direct effect to the amount of food waste generated by the household, because more food is needed (provisioned, cooked and served) in order to satisfy the needs for a larger number of family members (Silvennoinen et al., 2014; WRAP, 2009). In order to investigate the effect of the household size on the per capita generation of food waste, Table 2 is compiled. From there it is evident that as the members of the household increase, the per capita generation of food waste is decreasing. This result is in agreement with the original report by Quested et al. (2013) that the amount of food waste generated per capita decreases within increasing household size. It is also in agreement with later findings that single-member households generate more food waste on a per capita basis (Parizeau et al., 2015; Jörissen et al., 2015). Moreover, the report by WRAP (2009) states that people in four-person households generated approximately half the amount of food waste per capita compared to single-

Table 3. Annual per capita food waste generation in Greece per food item (kg/inh-y)

\begin{tabular}{ccccc}
\hline & Avoidable & Unavoidable & Total & \% avoidable/total \\
\hline Bread & $2.56( \pm 4.71)^{*}$ & $0.12( \pm 0.15)$ & $2.68( \pm 4.86)$ & 95.5 \\
\hline Raw meat/fish & $0.37( \pm 2.49)$ & $0.79( \pm 2.43)$ & $1.16( \pm 4.92)$ & 31.9 \\
\hline Fruits & $3.98( \pm 7.74)$ & $22.18( \pm 23.71)$ & $26.16( \pm 31.45)$ & 15.2 \\
\hline Vegetables & $5.34( \pm 21.10)$ & $21.98( \pm 20.55)$ & $27.32( \pm 41.65)$ & 19.5 \\
\hline Frozen vegetables & $0.15( \pm 1.30)$ & $0.00( \pm 0.00)$ & $0.15( \pm 1.30)$ & 100 \\
\hline Eggs & $0.08( \pm 0.38)$ & $0.40( \pm 1.14)$ & $0.48( \pm 1.52)$ & 16.7 \\
\hline Dairy & $4.36( \pm 7.95)$ & $0.07( \pm 0.32)$ & $4.43( \pm 8.27)$ & 98.4 \\
\hline Dry food & $0.98( \pm 3.64)$ & $0.41( \pm 1.14)$ & $1.39( \pm 4.78)$ & 70.5 \\
\hline Herbs & $0.06( \pm 0.33)$ & $0.98( \pm 2.02)$ & $1.04( \pm 2.35)$ & 5.8 \\
\hline Snacks & $0.45( \pm 1.22)$ & $0.11( \pm 0.86)$ & $0.56( \pm 2.08)$ & 80.4 \\
\hline Cooked food without meat/fish & $5.08( \pm 7.14)$ & $0.12( \pm 0.43)$ & $5.20( \pm 7.57)$ & 97.7 \\
\hline Cooked food with meat/fish & $1.81( \pm 3.38)$ & $2.28( \pm 4.17)$ & $4.09( \pm 7.55)$ & 44.3 \\
\hline Deserts & $0.49( \pm 1.57)$ & $0.00( \pm 0.03)$ & $0.49( \pm 1.60)$ & 100.0 \\
\hline Other & $0.18( \pm 0.89)$ & $0.77( \pm 0.09)$ & $0.95( \pm 0.98)$ & 18.9 \\
\hline Total & 25.89 & 50.21 & 76.10 & 34
\end{tabular}

Table 3 presents the per capita avoidable and unavoidable food waste generation per food category. For each food category, the percentage that the avoidable fraction represents to the total amount generated, is also presented. From these results (Table 3 ) it is evident that occupancy homes. This statement is also true for our findings (see Table 2).

In order to further demonstrate the effect of household size on the per capita generation of food waste, linear regression was tested to the results of Table 2 . The linear regression model is statistically significant $(p=0.0023$ $<0.05)$ just for the results corresponding to the avoidable fraction of food waste generated. The linear equation resulting from the regression is the following:

Avoidable food waste generation ( $\mathrm{kg} / \mathrm{inh}-\mathrm{y})=-6.457$ (household size $)+45.53\left(R^{2}=0.9229\right)$

The results of the present study (see Table 3 ) indicate that $34.0 \%$ of the overall food waste generated is avoidable, corresponding to $25.9 \mathrm{~kg} / \mathrm{inh}-\mathrm{y}$. This value is close to the respective reported for Finland (Koivupuro et al., 2012).

\footnotetext{
* Numbers in parentheses correspond to the standard deviation of each figure.
}

the prevention efforts should focus on the prevention of cooked food without meat or fish (namely pasta and rice), deserts, bread and dairy products wastage by Greek households, since in these food items the percentage of the avoidable fraction food waste is over $95 \%$. 
The avoidable fraction of food waste presents the highest potential for prevention. The avoidable food fraction can be further be split as cooked food that was not consumed and as food items that were not consumed before their expiration date. In order to prioritize the prevention potential, an analysis of the contribution of each food item to the total generated avoidable food waste should be performed. From the analysis of the results (see Figure 1), the avoidable food waste fraction consisted mainly of vegetables (21\%), cooked food without meat $(20 \%)$, dairy products $(17 \%)$, fruits $(15 \%)$, and bread $(10 \%)$.

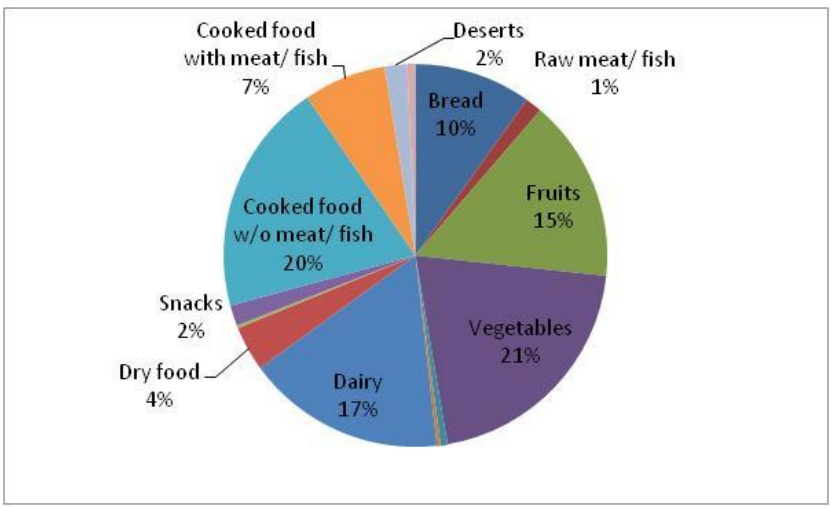

Figure 1. Food waste composition of the avoidable fraction

Compared to similar self-reporting studies, Szabó-Bódi et al. (2018) report that the percentage of the avoidable food waste in Hungary was $48.7 \%$ (corresponding to $33.14 \mathrm{~kg}$ per capita per year) and that the most frequently wasted food categories were meals and bakery products. Delley and Brunner (2018) report that $44 \%$ of the avoidable food waste in Switzerland belongs to the aggregated category of fruits, vegetables, potatoes, and herbs followed by bread and bakery products (17\%). Compared to the aforementioned results by Delley and Brunner (2018) and Szabó-Bódi et al. (2018) we can identify common food items in the avoidable food waste fraction such as meals and bakery products. Moreover, vegetables and fruits were found to be major components of the avoidable food waste fraction in Greece in comparable proportions as those reported by Delley and Brunner (2018) in Switzerland.

Moreover, compared to the respective distribution for the avoidable food waste reported by WRAP (2009), the percentage of fruits is more than double; also, the percentage of cooked food (excluded meat and fish) is higher in Greece compared to the results of WRAP (2009). Both of the aforementioned results can be explained by the abundance of fruits and vegetables in Greece, including self-provision, compared to the UK and Hungary.

Note, also, that for some types of fruits and vegetables, WRAP (2009) reports that there are strong seasonal patterns in purchasing and waste. It is also reported that among the various food items, vegetables and fruits have the highest wastage rates as they are often overpurchased because they are generally cheaper compared to other food groups like meat and fish. The overstocking by consumers of vegetables and fruits, combined with their shorter shelf life, yields to increased food waste generation rates.

Figure 2 presents the results of the unavoidable food waste fraction. It consists mainly of vegetable peelings (44\%) and fruit skins and cores (44\%). Note that during the sampling period typical vegetables (e.g. lettuces) and fruits of the Mediterranean summer (such as watermelons) were abundant in the examined households, based on the written notes of the diaries. In watermelons, Manios et al. (2005) reported that the inedible, and therefore unavoidably wasted, fraction is quite high corresponding to $0.617 \mathrm{~kg}$ of residue per $\mathrm{kg}$ of fruit.

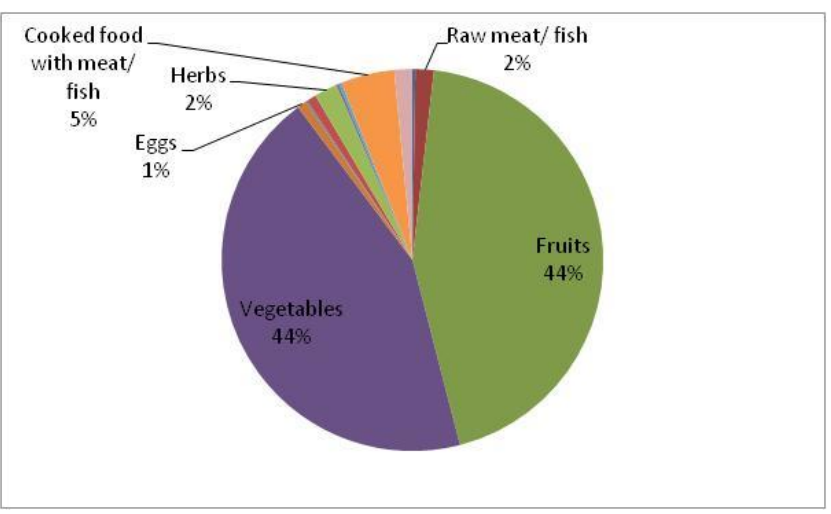

Figure 2. Food waste composition of the unavoidable fraction

Moreover, food waste can be classified as animal based or as plant derived (Edjabou et al., 2016; WRAP, 2009). Animal based products have much higher environmental footprint compared to those of derived from plants (Nijdam et al., 2012). In our case raw meat/fish, eggs, dairy products, cooked meat/fish and desserts are classified as animal based products. On the other hand, bread, fruits, vegetables (raw and frozen), dry food, herbs, snacks and cooked food without meat/fish (mainly corresponding to pasta and rice) are classified as plant derived products. Figure 4 presents the distribution of the generated food waste as animal based or plant derived.

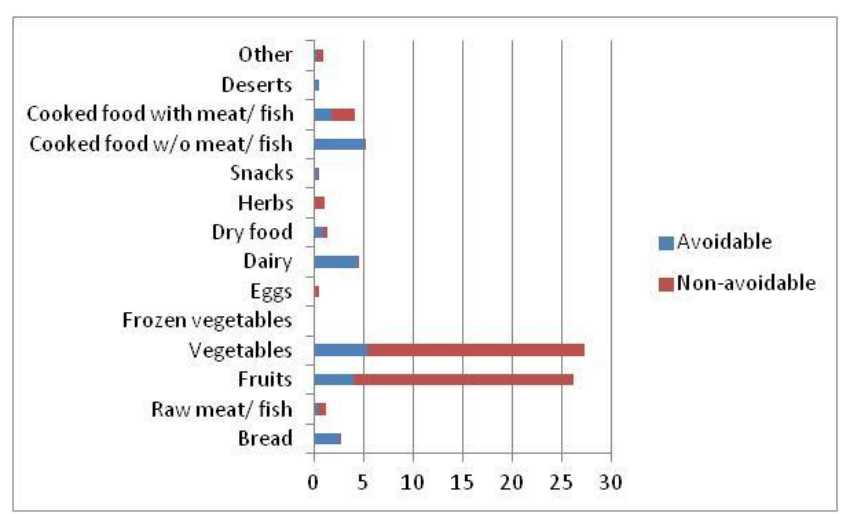

Figure 3. Average composition of Greek households food waste (\% mass per wet basis) based on food categories

Edjabou et al. (2016) also classify food waste as processed or unprocessed. Generally speaking, the environmental 
and financial losses associated to processed food are higher that the respective of unprocessed food. In our case, bread, frozen vegetables, dairy products, dry food, snacks, cooked food (both with and without meat/fish) and desserts are classified as processed food. On the other hand, raw meat/fish, fruits, vegetables, eggs and herbs are the unprocessed food items. Figure 4 presents the distribution of food waste as processed or unprocessed.

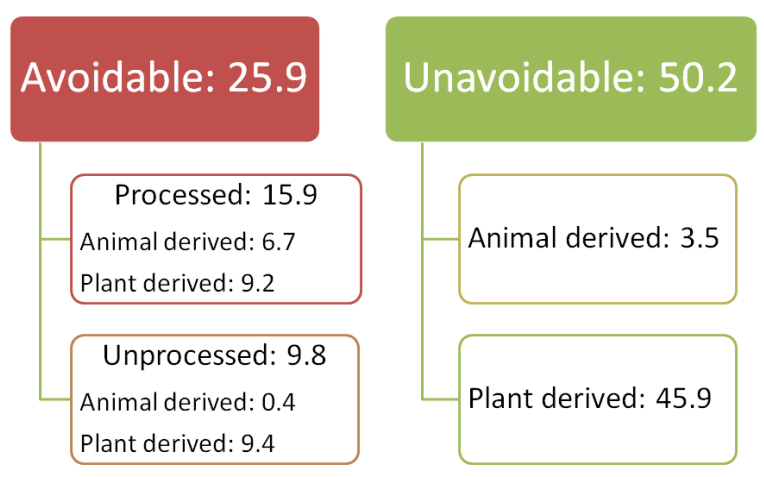

Figure 4. Food waste generation rate distribution in households in Greece in $\mathrm{kg}$ wet mass per capita per year

The main limitation of our study is that the use of diaries for recording food that is thrown away from households is a methodology that underestimates the food wasted in households because households tend to be cautious when they know that they have to weigh and report the amount of food that they throw away (Visschers et al., 2016). Moreover, there is a lack of other demographic data of the participating households (e.g. income of the household, educational level of the respondent) that could possibly have an effect on the household food waste generation rates.

\section{Conclusions}

A field research has been performed for the first time in Greece focusing on the generation of food waste by households. The total food waste generation was measured to be $76.1 \pm 68.3 \mathrm{~kg} / \mathrm{inh}-\mathrm{y}$; this number is the sum of the avoidable $(25.9 \pm 34.9 \mathrm{~kg} / \mathrm{inh}-\mathrm{y})$ and the unavoidable $(50.2 \pm 47.1 \mathrm{~kg} / \mathrm{inh}-\mathrm{y})$ fractions. The food waste generation values measured in this study are within the ranges reported for other developed European countries. Moreover, the results indicate that the avoidable per capita generation for four-member households, measured to $20.3 \mathrm{~kg} / \mathrm{inh}-\mathrm{y}$, is almost half of the respective for single member households (measured to $38.7 \mathrm{~kg} / \mathrm{inh}-\mathrm{y})$.

Based on our measurements, the key components of the avoidable food waste fraction are vegetables (21\%), cooked food without meat or fish $(20 \%)$, dairy products $(17 \%)$, fruits $(15 \%)$, and bread $(10 \%)$. On the unavoidable fraction, vegetable peelings (44\%) and fruit skins and cores (44\%) dominate in almost identical percentages. Waste prevention efforts should focus on the food items of the avoidable fraction that present the highest percentages, are animal derived and processed, and therefore have the highest prevention potential.

\section{References}

Abeliotis K., Lasaridi K. and Chroni C. (2016), Food Waste Prevention in Athens, Greece: The Effect of Family Characteristics, Waste Management \& Research, 34, 1210-1216.

Abeliotis K., Lasaridi K. and Chroni C. (2014), Attitudes and behaviour of Greek households regarding food waste prevention, Waste Management \& Research, 32, 237- 240.

Delley M. and Brunner T.A. (2018), Household food waste quantification: comparison of two methods, British Food Journal, 120, 1504-1515.

Edjabou M.E., Petersen C., Scheutz C. and Astrup T.F. (2016), Food waste from Danish households: Generation and composition, Waste Management, 52, 256-268.

European Commission (2010), Preparatory study on food waste across EU-27. Technical Report-2010-054, European Communities. 2010. ISBN: 978-92-79-22138-5, DOI: 10.2779/85947.

Gustavsson J., Cederberg C., Sonesson U., et al. Global Food Losses and Waste. Extent, Causes and Prevention. FAO, Rome 2011. From: http://www.fao.org/docrep/014/mb060e /mb060e00.pdf. Accessed 20 April 2019.

Helstat (2014), Census of Greece 2011. From: https://www. statistics.gr/documents/20181/1210503/A1602_SAM01_DT _DC_00_2011_03_F_GR.pdf/e1ac0b1c-8372-4886-acb8-d00 a5a68aabe Accessed 20 April 2019.

Jörissen J., Priefer C. and Bräutigam K.-R. (2015), Food Waste Generation at Household Level: Results of a Survey among Employees of Two European Research Centers in Italy and Germany, Sustainability, 7, 2695-2715.

Koivupuro H.-K., Hartikainen H., Silvennoinen K., et al. (2012), Influence of socio-demographical, behavioural and attitudinal factors on the amount of avoidable food waste generated in Finnish households, International Journal of Consumer Studies, 36, 183-191.

Manios Y., Harizani K., Markakis G., Galani P. and Manios Th. (2005), Relating fruit and vegetable consumption in households with residue generation and utilization in the city of Heraklion, Crete, Greece, International Journal of Sustainable Development \& World Ecology, 12, 1-9.

Nijdam D., Rood T. and Westhoek H. (2012), The price of protein: Review of land use and carbon footprints from life cycle assessments of animal food products and their substitutes, Food Policy, 37, 760-770.

Parizeau K., von Massow M. and Martin R. (2015), Household level dynamics of food waste production and related beliefs, attitudes and behaviours in Guelph: Ontario, Waste Management, 35, 207-217.

Ponis S.T., Papanikolaou P.A., Ntalla A.C. and Xenos K.I. (2017), Household Food Waste in Greece: A Questionnaire Survey, Journal of Cleaner Production, 149, 1268-1277.

Quested T.E., Marsh E., Stunell D. et al. (2013), Spaghetti soup: The complex world of food waste behaviours, Resources, Conservation, Recycling, 79, 43-51. 
Silvennoinen K., Katajajuuri J.-M., Hartikainen H., Heikkilä L. and Reinikainen A. (2014), Food waste volume and composition in Finnish households, British Food Journal, 116, 1058-1068.

Szabó-Bódi B., Kasza G., and Szakos D. (2018), Assessment of household food waste in Hungary, British Food Journal, 120, 625-638.

Schneider F. (2013), Review of food waste prevention on an international level, Waste and Resource Management, 166, 187-203.

Thyberg K.L. and Tonjes D.J. (2016), Drivers of food waste and their implications for sustainable policy development, Resources, Conservation and Recycling, 106, 110-123.

Visschers V.H., Wickli N. and Siegrist M. (2016), Sorting out food waste behaviour: A survey on the motivations and barriers of self-reported amounts of food waste in households, Journal of Environmental Psychology, 45, 66-78. 